\title{
Peripheral Collateral Blood Flow and Vascular Reactivity in the Dog*
}

\author{
Jay D. Coffman $\dagger$ \\ (From the Department of Medicine, University Hospital, Boston University Medical Center, \\ Boston, Mass.)
}

Arterial blood vessels running collaterally to the main artery supplying a limb may be of vital importance to the survival of the limb when the main artery is obstructed. Whether such collateral vessels dilate or constrict in response to vasoactive procedures has not been clearly established. Studies of collateral blood flow in man and animals usually have not determined whether vasoactivity of the collateral arteries or changes in the peripheral vessels of the limb caused the alterations in collateral blood flow (1-4). Those studies that have considered collateral vascular resistance do not agree in their conclusions concerning collateral vascular reactivity (5-7). In the present study two questions were investigated: 1) what procedures can increase or decrease collateral blood flow, and 2) do collateral vessels dilate and constrict?

Collateral blood flow was measured as the venous outflow from the dog's hindlimb with acute or chronic main arterial obstruction; collateral vascular resistance was calculated as the pressure difference across the collateral vessels divided by the venous outflow. Changes in vascular resistance were used to reflect vasoactivity of the vessels involved. The effects of several different procedures on collateral blood flow and vascular resistance were studied. Since collateral flow was large in the hindlimb experiments, similar studies in the forelimb were performed to investigate the reactions of a more limited collateral vasculature.

The experiments on hindlimbs with acutely or chronically ligated main arteries demonstrated a large collateral blood flow that could be affected

\footnotetext{
* Submitted for publication July 23, 1965; accepted March 2, 1966.

Supported by grants HE07963 and 5-P01-HE07299 from the National Institutes of Health.

$\dagger$ Address requests for reprints to Dr. Jay D. Coffman, University Hospital, 750 Harrison Ave., Boston, Mass. 02118.
}

by each of the procedures tested. Alterations in collateral flow were qualitatively similar to total blood flow changes found in normal hindlimbs. Vasodilatation of the collateral vessels was demonstrated, but vasoconstriction was obvious only in acutely ligated dogs during depression of systemic arterial pressure. Certain differences were found in the reactions of the collateral vasculature of the forelimb as compared to the hindlimb, but were considered explained by differences in the number and tonus of the collateral blood vessels in the two preparations.

\section{Methods}

Adult mongrel dogs were anesthetized with approximately $30 \mathrm{mg}$ per $\mathrm{kg}$ of intravenous pentobarbital. An endotracheal tube was inserted and the dog allowed to breathe room air. Heparin was used as the anticoagulant $(1,000 \mathrm{U}$ per $\mathrm{kg}$ initially, and $500 \mathrm{U}$ per $\mathrm{kg}$ every $30 \mathrm{~min}-$ utes). In all acute experiments, the femoral artery of the experimental limb was dissected from the level of the deep femoral artery to the caudal femoral and popliteal arterial branches (8). The internal iliac artery was tied within the abdomen about $3 \mathrm{~cm}$ above the inguinal ligament. The deep femoral, cranial femoral, caudal superficial epigastric, and superficial circumflex iliac arteries were also ligated. In all dogs, the paw vessels of the experimental limb were excluded from the system by 2 tight ligatures. In 4 acute experiments, the hindlimb was skinned and wrapped in warm saline-soaked gauze.

In 7 acute experiments, the femoral artery was severed and rejoined by a cannula that allowed blood to flow to the leg either directly or after being shunted through a continuously recording rotameter. Hindlimb venous outflow was measured by cannulating the external iliac vein just above the inguinal ligament through a medial branch. The cannulation was above the entry of the caudal femoral and cranial femoral veins. The external iliac vein was tied above the point of cannulation, and the blood flow from the vein was shunted through a second rotameter to the femoral vein of the opposite limb. In these dogs, rotameter measurements of arterial inflow and venous outflow were compared during rest and muscle stimulation of the hindlimb.

In 31 experiments, only external iliac venous outflow was measured (as described above) and, after the fem- 
oral artery was clamped or tied at the inguinal ligament, venous outflow was considered to be "collateral blood flow" (acutely ligated dogs).

In 22 experiments, dogs were prepared at least 3 weeks before being studied (chronically ligated dogs). Under sterile conditions, a 2-cm segment of the external iliac artery was ligated as close to its origin from the aorta as possible through an abdominal incision. At the time of testing, all dogs had at least a weakly perceptible pulse in the femoral artery below the ligated external iliac artery. Only two animals developed weakness (apparent during walking) of the operated hindlimb. Collateral blood flow (venous outflow) was measured as in the acute experiments. At the conclusion of all chronic experiments, the external iliac ties were inspected and in all cases were found to be intact.

In 5 experiments, forelimb collateral blood flow was studied after the subclavian artery was tied close to its origin and the axillary artery was ligated in the axilla. Venous return from catheters in the axillary and cephalic veins was measured by a rotameter and returned to the dog via an external jugular vein.

In 1 chronically and 6 acutely ligated dogs, retrograde femoral arterial blood flow (blood flowing through collateral vessels into the femoral artery below its site of occlusion) was measured as follows: the femoral artery was ligated at the inguinal ligament; a catheter was inserted below the ligation distally into the femoral artery to allow the blood flow to be shunted through a rotameter to an external jugular vein. External iliac venous outflow was also measured as described above.

Mean sytemic arterial pressure was recorded through a catheter in a common carotid or femoral artery by means of a Sanborn pressure transducer (model $267 \mathrm{~B}$ ). In most dogs, the mean local arterial pressure was also measured below the point of occlusion in the femoral (or axillary) artery via a 22 -gauge needle and Sanborn pressure transducer. Recordings of blood flow and mean arterial pressure were made with a Sanborn direct writing recorder.

The following procedures were tested in both acutely and chronically ligated dogs to determine their effects on the circulation in a limb with an obstructed main artery: 1) Exercise was simulated by stimulating the limb with a 60 -cycle electrical stimulator at a rate of 60 stimuli per minute via two electrodes inserted into the thigh muscles. In each dog, light, medium, and strong exercise was produced by varying the voltage; voltages ranged from 0.25 to $100 \mathrm{v}$. 2) With a constant infusion pump, bradykinin, norepinephrine bitartrate, or epinephrine hydrochloride was administered into the aorta or into the femoral artery below the level of arterial occlusion. 3) Isoproterenol hydrochloride, norepinephrine bitartrate, or epinephrine hydrochloride was administered intravenously by a constant infusion pump into an external jugular vein at the rate of $1 \mathrm{ml}$ per minute for 6 minutes. 4) Mechanical elevations and depressions of systemic blood pressure (measured through a catheter in a common carotid artery) were produced by raising or lowering a reservoir of donor dog blood connected to the experimental animal's aorta by a cannula inserted via a femoral artery; changes in pressure were maintained until a steady blood flow occurred (average 4 minutes). 5) The hindlimb blood flow was studied during reactive hyperemia after a 60-second aortic occlusion (just below the renal arteries). Aortic occlusion did not always deprive the limb of all blood flow, for a small amount of venous outflow continued even during longer aortic occlusion periods. Reactive hyperemic blood flows and flow debts were calculated as described in a previous paper (9). Flow debt is defined as the amount of blood flow to the hindlimb that would have occurred during aortic occlusion.

One to three procedures were tested in each experiment. In 3 dogs, blood flow of the hindlimb was studied when the femoral artery was not clamped.

At the beginning or end of experiments, blood was drawn simultaneously from the carotid artery, the femoral or axillary artery below the occlusion, the femoral or axillary vein of the experimental limb (collateral venous blood), and the contralateral femoral or brachial vein. Blood samples were always drawn after the animal had been in a resting state for at least 5 minutes. Oxygen content of these blood samples was analyzed in duplicate by the method of Van Slyke and Neill (10). Arterial blood samples were obtained periodically during the experiments from a common carotid artery and analyzed for oxygen content. Serial hematocrit counts were performed and did not change by more than $5 \%$ during individual experiments. At the end of each experiment, the rotameter was calibrated with the experimental animal's blood.

Collateral arterial resistance was calculated by dividing the difference between systemic arterial pressure and the local arterial pressure below the obstruction by venous outflow (millimeters $\mathrm{Hg}$ per milliliter per minute) (11). In this calculation of collateral arterial resistance, two assumptions are made. First, the venous outflow as measured in these experiments is an adequate reflection of the arterial inflow to the limb. Second, most of the collateral arterial vessels empty into the femoral artery below the obstruction, and there is no sizable collateral arterial bed that empties directly into the femoral vein. If these assumptions are true, then the femoral arterial pressure below the obstruction will represent the driving force for the entire venous outflow measured. The experimental data help to substantiate these assumptions as will be elaborated upon in the Discussion. Total limb vascular resistance was calculated by dividing the mean systemic arterial pressure by the venous outflow. Local vascular resistance in the limb was calculated by dividing the mean local arterial pressure below the arterial occlusion by venous outflow. These calculations of total resistance and local resistance were known not to be exact, since venous pressure was not zero as implied. Statistical analyses were performed as described by Snedecor (12); all statistical results were obtained by the Student $t$ test with each dog serving as his own control (paired $t$ test). A probability level less than 0.05 
was considered significant. Mean values and their standard errors are given.

\section{Results}

Arterial inflow and venous outflow. In 7 acute experiments, femoral arterial inflow and venous outflow of the unobstructed hindlimb were measured simultaneously during rest and muscle stimulation. Table I depicts the average results; arterial inflow usually, but not always, exceeded venous outflow. The increases in arterial and venous blood flow during exercise were significantly different $(p<0.05)$ for each grade of stimulation when compared with both resting blood flow and the increase in blood flow found at the previous grade of muscle stimulation (paired $t$ test). Average venous outflow remained in constant ratio to average arterial inflow; there were no significant differences between the ratios at any grade of exercise compared to the resting ratio.

Collateral blood flow (venous outflow during arterial occlusion). When the femoral artery was occluded, venous outflow and blood pressure below the occlusion fell immediately to approximately one-third of the previous level, and then both rose slowly for 2 to 5 minutes. The venous outflow was considered to represent collateral flow once flow and pressure had reached stable levels. In the hindlimb experiments with acute ligation of the femoral artery, average collateral flow (venous outflow) was $24.1 \pm 2.4 \mathrm{ml}$ per minute, and mean local arterial pressure below the obstruction averaged 88 compared to a systemic pressure of $134 \mathrm{~mm} \mathrm{Hg}$. In the dogs with chronic ligations, collateral flow averaged 36.5

TABLE I

Femoral arterial inflow versus venous outflow during rest and exercise

\begin{tabular}{lccc}
\hline \hline & $\begin{array}{c}\text { Arterial } \\
\text { inflow }\end{array}$ & $\begin{array}{c}\text { Venous } \\
\text { outflow }\end{array}$ & $\begin{array}{c}\text { Ratio of } \\
\text { venous outflow } \\
\text { to arterial } \\
\text { inflow }\end{array}$ \\
\hline Resting & $m l / m i n$ & $m l / m i n$ & \\
Light stimulation & $45.6 \pm 8.8 *$ & $34.9 \pm 5.1$ & $0.80 \pm 0.06$ \\
Resting & $50.9 \pm 8.7$ & $41.4 \pm 5.4$ & $0.84 \pm 0.05$ \\
Medium stimulation & $34.3 \pm 3.9$ & $26.5 \pm 2.6$ & $0.79 \pm 0.06$ \\
Resting & $55.2 \pm 5.8$ & $47.7 \pm 4.2$ & $0.88 \pm 0.05$ \\
Strong stimulation & $30.5 \pm 2.6$ & $23.6 \pm 2.3$ & $0.78 \pm 0.04$ \\
\hline
\end{tabular}

* Standard error in all Tables.
TABLE II

Exercise and collateral blood flow and vascular resistance*

\begin{tabular}{lcccc}
\hline & Collateral flow & CR & LR \\
\hline & $m l / m i n$ & $m m ~$ & & \\
& & & \\
& & & \\
Acutely ligated hindlimbs & & & \\
Control & $25.9 \pm 4.0$ & $2.4 \pm 0.3$ & $3.3 \pm 0.6$ \\
Light stimulation & $36.6 \dagger \pm 2.5$ & $2.0 \dagger \pm 0.3$ & $1.6 \dagger \pm 0.3$ \\
Medium stimulation & $52.0 \dagger \pm 4.7$ & $1.6 \dagger \pm 0.2$ & $0.9 \dagger \pm 0.2$ \\
Strong stimulation & $70.5 \dagger \pm 8.0$ & $1.3 \dagger \pm 0.2$ & $0.5 \dagger \pm 0.1$ \\
Chronically ligated hindlimbs & & & \\
Control & $40.7 \pm 2.6$ & $2.9 \pm 0.2$ & $3.8 \pm 0.5$ \\
Light stimulation & $48.7 \dagger \pm 3.2$ & $2.3 \dagger \pm 0.1$ & $2.1 \dagger \pm 0.4$ \\
Medium stimulation & $75.1 \dagger \pm 5.9$ & $1.8 \dagger \pm 0.1$ & $1.1 \dagger \pm 0.1$ \\
Strong stimulation & $114.9 \dagger \pm 11.5$ & $1.5 \dagger \pm 0.2$ & $0.6 \dagger \pm 0.1$ \\
Forelimb experiments & & & & \\
Control & $12.8 \pm 2.1$ & $6.6 \pm 0.9$ & $5.3 \pm 1.3$ \\
Light stimulation & $13.4 \pm 2.5$ & $9.4 \pm 2.1$ & $2.5 \dagger \pm 0.6$ \\
Medium stimulation & $11.7 \pm 1.8$ & $10.6 \pm 2.4$ & $1.7 \dagger \pm 0.4$ \\
Strong stimulation & $12.1 \pm 2.7$ & $10.0 \dagger \pm 1.2$ & $1.1 \dagger \pm 0.4$ \\
\hline
\end{tabular}

* $\mathrm{CR}=$ collateral vascular resistance $\mathrm{LR}=$ local limb resistance below the obstruction.

† Significant increases in flow or decreases in resistance $(p<0.05)$ Comparisons are made to control and to previous exercise values (paired

$\ddagger$ Significant increase in resistance compared to control value.

$\pm 3.8 \mathrm{ml}$ per minute, and mean local blood pressure averaged 112 compared to a systemic pressure of $130 \mathrm{~mm} \mathrm{Hg}$. In the forelimb experiments, collateral flow averaged $11.1 \pm 2.7 \mathrm{ml}$ per minute, and mean local arterial pressure averaged $53 \mathrm{com}$ pared to a systemic pressure of $148 \mathrm{~mm} \mathrm{Hg}$.

Results obtained in the 4 hindlimb experiments in which the skin was removed were qualitatively similar to experiments in which the skin remained intact. However, blood flows were much smaller, and therefore the data are not included in the following average results.

Exercise. In 5 acutely and 6 chronically ligated dogs, collateral blood flow (venous outflow) was measured at rest and during muscle stimulation. Table II shows that with increasing strength of muscle contraction, the collateral flow increased progressively and significantly in both groups of dogs. Collateral vascular resistance decreased significantly in both the acute and chronic ligations. Local arterial pressure below the obstruction fell to low levels during exercise and returned in an average of 90 seconds to control levels when exercise was stopped.

In 4 forelimb experiments (subclavian and axillary arterial ties ${ }^{1}$ ), no significant changes in col-

1 Three dogs were studied in which the axillary artery was tied deep in the axilla only. Results in these experiments were very similar to the hindlimb experiments. 
lateral flow occurred with muscle stimulation (Table II). Despite significant decreases in local limb vascular resistance, collateral resistance increased with each grade of muscle stimulation; the increase was significant only with strong muscle exercise. After exercise, the return of local arterial pressure to control levels was slow (averaging 230 seconds) compared to the hindlimb experiments.

Intra-aortic and intra-arterial (distal to the obstruction) infusion of drugs. In 5 acutely and 11 chronically ligated dogs, bradykinin, $1 \mu \mathrm{g}$ per minute, was administered either by intra-aortic infusion so as to reach the collateral vessels, or by intra-arterial infusion below the arterial tie so as to avoid them (Table III). A significant in-

TABLE III

Intra-aortic $(A)$ and intra-arterial $(a)^{*}$ drugs and collateral blood flow and vascular resistance

\begin{tabular}{|c|c|c|c|}
\hline & Collateral flow & CR & LR \\
\hline Acutely ligated hindlimbs & $\mathrm{ml} / \mathrm{min}$ & \multicolumn{2}{|c|}{$m m \mathrm{Hg} / \mathrm{ml} / \mathrm{min}$} \\
\hline $\begin{array}{l}\text { Control } \\
\text { Bradykinin } 1 \mu \mathrm{g} / \mathrm{min} \text { (a) } \\
\text { Control } \\
\text { Bradykinin } 1 \mu \mathrm{g} / \mathrm{min} \text { (A) }\end{array}$ & $\begin{array}{l}31.7 \pm 5.2 \\
38.6 \dagger \pm 7.3 \\
30.0 \pm 5.6 \\
68.5 \dagger \pm 21.4\end{array}$ & $\begin{array}{l}2.0 \pm 0.5 \\
1.9 \pm 0.5 \\
2.8 \pm 0.9 \\
1.5 \dagger \pm 0.5\end{array}$ & $\begin{array}{l}3.1 \pm 0.4 \\
2.2 \dagger \pm 0.3 \\
2.5 \pm 0.3 \\
1.1 \dagger \pm 0.4\end{array}$ \\
\hline $\begin{array}{l}\text { Control } \\
\text { Norepinephrine } 6 \mu \mathrm{g} / \mathrm{min} \text { (a) } \\
\text { Control } \\
\text { Norepinephrine } 6 \mu \mathrm{g} / \mathrm{min} \text { (A) }\end{array}$ & $\begin{array}{l}30.6 \pm 0.3 \\
19.5 \dagger \pm 0.1 \\
27.4 \pm 4.2 \\
29.3 \pm 1.0\end{array}$ & $\begin{array}{l}1.9 \pm 0.7 \\
1.2 \pm 0.9 \\
2.0 \pm 0.9 \\
1.7 \pm 0.5\end{array}$ & $\begin{array}{l}2.2 \pm 03 \\
5.0 \dagger \pm 0.1 \\
3.1 \pm 0.3 \\
2.9 \pm 0.1\end{array}$ \\
\hline $\begin{array}{l}\text { Control } \\
\text { Epinephrine } 6 \mu \mathrm{g} / \mathrm{min} \text { (a) } \\
\text { Control } \\
\text { Epinephrine } 6 \mu \mathrm{g} / \mathrm{min}(\mathrm{A})\end{array}$ & $\begin{array}{l}32.6 \pm 5.6 \\
20.2 \dagger \pm 6.2 \\
36.0 \pm 11.5 \\
30.1 \pm 4.3\end{array}$ & $\begin{array}{l}1.6 \pm 0.7 \\
0.4 \pm 0.4 \\
1.7 \pm 0.8 \\
1.7 \pm 1.0\end{array}$ & $\begin{array}{l}2.0 \pm 0.1 \\
5.3 \dagger \pm 1.8 \\
1.7 \pm 0.3 \\
2.2 \pm 0.2\end{array}$ \\
\hline \multicolumn{4}{|l|}{ Chronically ligated hindlimbs } \\
\hline $\begin{array}{l}\text { Control } \\
\text { Bradykinin } 1 \mu \mathrm{g} / \mathrm{min} \text { (a) } \\
\text { Control } \\
\text { Bradykinin } 1 \mu \mathrm{g} / \mathrm{min} \text { (A) }\end{array}$ & $\begin{array}{l}35.1 \pm 10.6 \\
45.6 \dagger \pm 13.6 \\
39.9 \pm 14.4 \\
79.4 \dagger \pm 6.0\end{array}$ & $\begin{array}{l}1.3 \pm 0.7 \\
1.1 \pm 0.4 \\
1.5 \pm 0.9 \\
0.5 \dagger \pm 0.2\end{array}$ & $\begin{array}{l}2.7 \pm 1.0 \\
1.3 \dagger \pm 0.3 \\
3.2 \pm 1.5 \\
0.9 \dagger \pm 0.1\end{array}$ \\
\hline $\begin{array}{l}\text { Control } \\
\text { Norepinephrine } 6 \mu \mathrm{g} / \mathrm{min} \text { (a) } \\
\text { Control } \\
\text { Norepinephrine } 6 \mu \mathrm{g} / \mathrm{min} \text { (A) }\end{array}$ & $\begin{array}{l}32.7 \pm 5.3 \\
17.4 \dagger \pm 4.1 \\
36.2 \pm 2.9 \\
34.6 \pm 12.3\end{array}$ & $\begin{array}{l}1.6 \pm 0.5 \\
2.0 \pm 0.7 \\
1.2 \pm 0.9 \\
1.5 \pm 1.1\end{array}$ & $\begin{array}{l}2.4 \pm 0.3 \\
5.7 \dagger \pm 1.3 \\
2.4 \pm 0.3 \\
3.0 \pm 1.4\end{array}$ \\
\hline $\begin{array}{l}\text { Control } \\
\text { Epinephrine } 6 \mu \mathrm{g} / \mathrm{min}(\mathrm{a}) \\
\text { Control } \\
\text { Epinephrine } 6 \mu \mathrm{g} / \mathrm{min}(\mathrm{A})\end{array}$ & $\begin{array}{l}37.1 \pm 10.5 \\
26.3 \dagger \pm 11.8 \\
30.1 \pm 9.3 \\
35.0 \pm 15.1\end{array}$ & $\begin{array}{l}1.5 \pm 0.8 \\
1.8 \pm 1.3 \\
1.3 \pm 1.0 \\
1.5 \pm 1.4\end{array}$ & $\begin{array}{l}2.6 \pm 0.8 \\
6.0 \dagger \pm 3.0 \\
2.4 \pm 0.6 \\
3.4 \pm 1.6\end{array}$ \\
\hline \multicolumn{4}{|l|}{ Forelimb experiments } \\
\hline $\begin{array}{l}\text { Control } \\
\text { Bradykinin } 1 \mu \mathrm{g} / \mathrm{min} \text { (a) } \\
\text { Control } \\
\text { Bradykinin } 1 \mu \mathrm{g} / \mathrm{min} \text { (A) }\end{array}$ & $\begin{array}{l}14.9 \pm 3.7 \\
15.3 \pm 3.2 \\
14.6 \pm 3.6 \\
19.4 \pm 6.7\end{array}$ & $\begin{array}{l}6.4 \pm 1.4 \\
6.6 \pm 1.2 \\
6.5 \pm 1.1 \\
7.3 \pm 2.3\end{array}$ & $\begin{array}{l}5.0 \pm 1.2 \\
3.5 \dagger \pm 0.6 \\
4.9 \pm 1.1 \\
2.1 \dagger \pm 0.5\end{array}$ \\
\hline $\begin{array}{l}\text { Control } \\
\text { Norepinephrine } 6 \mu \mathrm{g} / \mathrm{min} \text { (a) } \\
\text { Control } \\
\text { Norepinephrine } 6 \mu \mathrm{g} / \mathrm{min} \text { (A) }\end{array}$ & $\begin{array}{l}8.9 \pm 1.0 \\
3.4 \dagger \pm 0.6 \\
9.9 \pm 0.5 \\
4.4 \dagger \pm 0.6\end{array}$ & $\begin{array}{r}9.7 \pm 1.0 \\
12.6 \pm 2.0 \\
8.2 \pm 0.7 \\
9.5 \pm 0.9\end{array}$ & $\begin{array}{r}6.1 \pm 0.7 \\
29.9 \dagger \pm 9.5 \\
5.6 \pm 0.7 \\
23.7 \dagger \pm 3.3\end{array}$ \\
\hline
\end{tabular}

* Intra-arterial drugs were infused distal to the arterial obstruction t Significant change from control values $(p<0.05)$ by paired $t$ test. crease in collateral flow (venous outflow) occurred during infusion by either route; however, increases were much greater when the bradykinin was administered into the aorta above the obstruction, in both acutely and chronically ligated dogs. A significant decrease in collateral resistance occurred when bradykinin reached the collaterals by the intra-aortic route. Collateral resistance was not significantly altered when bradykinin was administered below the obstruction.

Norepinephrine and epinephrine ( $6 \mu \mathrm{g}$ per minute) produced a significant decrease in collateral blood flow only by the intra-arterial route of administration in both acutely and chronically ligated dogs. The intra-aortic route of infusion usually caused a rise in systemic arterial pressure when a concentration of the drug large enough to affect collateral flow was given. No significant changes in collateral resistance were observed.

In the forelimb experiments, bradykinin infusions intra-aortically or intra-arterially did not always increase collateral flow (Table III). When collateral blood flow did increase, the increases were larger when bradykinin was given above the arterial obstruction (intra-aortic). Local resistance showed significant decreases, whereas collateral resistance was not significantly changed during bradykinin infusion by either route. By either route of administration, norepinephrine infusion led to significant decreases in collateral flow and increases in local resistance, but collateral resistance was not significantly altered.

Intravenous drugs. Intravenous norepinephrine and epinephrine (12 $\mu \mathrm{g}$ per minute) produced a significant increase in hindlimb collateral blood flow in 6 acutely and 11 chronically ligated dogs (Table IV). The increase in blood flow could not be explained entirely by an increase in systemic arterial pressure, since local vascular resistance usually fell. Flow increases with isoproterenol (4 $\mu \mathrm{g}$ per minute) were small but significant in the acutely ligated dogs. The decrease in collateral resistance with these drugs was significant only for intravenous norepinephrine. In 3 dogs with unobstructed arterial inflow to the hindlimb, all three drugs produced increases in hindlimb venous outflow and decreases in total limb resistance.

Systemic arterial pressure. The effects of changes in systemic arterial pressure on hindlimb collateral flow were studied in 5 acutely and 5 
TABLE IV

Intravenous drugs and collateral blood flow and vascular resistance

\begin{tabular}{lccc}
\hline \hline & $\begin{array}{c}\text { Collateral } \\
\text { flow }\end{array}$ & CR & LR \\
\hline & $\mathrm{ml} / \mathrm{min}$ & $\mathrm{mm} \mathrm{Hg} / \mathrm{ml} / \mathrm{min}$ \\
Acutely ligated hindlimbs & & \multicolumn{2}{c}{} \\
Control & $23.9 \pm 3.4$ & $1.8 \pm 0.6$ & $2.8 \pm 0.5$ \\
Isoproterenol $4 \mu \mathrm{g} / \mathrm{min}$ & $26.5^{*} \pm 3.4$ & $1.4 \pm 0.5$ & $2.3 \pm 0.7$ \\
Control & $31.6 \pm 5.5$ & $2.0 \pm 0.6$ & $3.6 \pm 0.7$ \\
Norepinephrine 12 $\mu \mathrm{g} / \mathrm{min}$ & $52.2^{*} \pm 9.0$ & $0.6^{*} \pm 0.1$ & $1.8^{*} \pm 0.6$ \\
Control & $25.1 \pm 7.7$ & $2.0 \pm 0.6$ & $3.9 \pm 0.6$ \\
Epinephrine 12 $\mu \mathrm{g} / \mathrm{min}$ & $34.2^{*} \pm 6.6$ & $1.5 \pm 0.1$ & $3.3^{*} \pm 0.3$ \\
Chronically ligated hindlimbs & & & \\
Control & $40.2 \pm 4.9$ & $0.9 \pm 0.1$ & $2.4 \pm 0.2$ \\
Isoproterenol 4 $\mu \mathrm{g} / \mathrm{min}$ & $41.9 \pm 5.7$ & $0.9 \pm 0.1$ & $2.1 \pm 0.2$ \\
Control & $29.5 \pm 6.2$ & $0.9 \pm 0.1$ & $2.8 \pm 0.2$ \\
Norepinephrine 12 $\mu \mathrm{g} / \mathrm{min}$ & $54.8^{*} \pm 1.1$ & $0.7^{*} \pm 0.1$ & $1.7^{*} \pm 0.3$ \\
Control & $34.9 \pm 6.8$ & $0.9 \pm 0.3$ & $2.2 \pm 0.2$ \\
Epinephrine $12 \mu \mathrm{g} / \mathrm{min}$ & $55.2^{*} \pm 0.4$ & $0.8 \pm 0.2$ & $1.6^{*} \pm 0.2$ \\
\hline
\end{tabular}

* Significant change fron control values $(\mathrm{p}<0.05)$ by paired $t$ test.

chronically ligated dogs. Mechanical elevation of systemic arterial pressure (measured in a common carotid artery) caused an initial large increase in collateral flow followed by a decrease to a level that still significantly exceeded control flow ( Table V). Decreases in systemic arterial pressure led to significant decreases in collateral flow. In the acutely ligated dogs, collateral resistance showed a significant increase and decrease with blood pressure depression and elevation, respectively; in the chronically ligated dogs, the changes in collateral resistance, although in the same direction, were not statistically significant. Control studies before femoral arterial ligations showed significant changes in venous outflow and total limb resistance.

In the forelimb experiments, significant collateral flow changes occurred with the systemic arterial pressure alterations (Table V). However, instead of initial large increases in venous outflow with blood pressure elevations, there were small, steady increases. A significant increase in collateral resistance occurred during systemic arterial pressure depression.

Reactive hyperemia. Reactive hyperemia in the hindlimb (produced by 60 seconds of aortic occlusion) was studied in 7 dogs before (control) and after (collateral) acute femoral arterial occlusion. Collateral reactive hyperemic total blood flow, which averaged $11.7 \pm 2.9 \mathrm{ml}$, did not differ significantly from the controls, which averaged $13.9 \pm 1.7 \mathrm{ml}(\mathrm{p}>0.5)$. Flow debt repayments were variable but usually underpaid in both the control and collateral situations. Reactive hyperemia of the collateral circulation showed lower peak flows $(35.4 \pm 3.1$ versus $76.2 \pm 6 \mathrm{ml}$ per minute, $\mathrm{p}<0.001)$ and was of longer duration ( $94 \pm 8.2$ versus $74 \pm 3.8$ seconds, $p<0.02$ ) than the controls. During the peak reactive hyperemic flows, local resistance decreased from previous control values $(4.3 \pm 0.1$ to $2.7 \pm 0.2, \mathrm{p}<0.01)$; collateral resistance was not significantly changed $(5.3 \pm 0.8$ to $4.8 \pm 0.7, \mathrm{p}>0.05)$. Reactive hyperemic flow was also demonstrated in 7 chronically ligated dogs; reactive hyperemic total blood flow averaged $11.5 \pm 2.0 \mathrm{ml}$, and flow debts were underpaid.

Retrograde flow experiments. In the experiments in which retrograde flow was measured, the total blood flow (retrograde flow plus venous outflow) exceeded the previously measured venous outflow presumably because of the low resistance outlet provided by the rotameter circuit. Shunting of flow through the rotameter (to the jugular vein) decreased the venous outflow from the hindlimb. For example, in one dog, venous outflow

TABLE V

Blood pressure alterations and collateral blood flow and vascular resistance*

\begin{tabular}{|c|c|c|c|}
\hline & $\begin{array}{l}\text { Collateral } \\
\text { flow }\end{array}$ & CR & LR \\
\hline Acutely ligated hindlimbs & $m l / \min$ & \multicolumn{2}{|c|}{$m m \mathrm{Hg} / \mathrm{ml} / \mathrm{min}$} \\
\hline $\begin{array}{l}\text { Control } \\
\mathrm{BP}+13 \pm 2.2 \mathrm{~mm} \mathrm{Hg} \\
\text { Control } \\
\mathrm{BP}-20 \pm 4.6 \mathrm{~mm} \mathrm{Hg}\end{array}$ & $\begin{array}{r}15.5 \pm 4.5 \\
25.7 \dagger \pm 5.9 \\
13.6 \pm 6.0 \\
7.8 \dagger \pm 5.1\end{array}$ & $\begin{array}{l}5.6 \pm 1.5 \\
3.5 \dagger \pm 1.1 \\
3.4 \pm 0.6 \\
5.3 \dagger \pm 0.1\end{array}$ & $\begin{array}{l}4.2 \pm 0.5 \\
3.2 \dagger \pm 0.8 \\
3.3 \pm 0.5 \\
7.7 \dagger \pm 2.2\end{array}$ \\
\hline \multicolumn{4}{|l|}{ Chronically ligated hindlimbs } \\
\hline $\begin{array}{l}\text { Control } \\
\text { BP }+13.5 \pm 3.9 \mathrm{~mm} \mathrm{Hg} \\
\text { Control } \\
\mathrm{BP}-47.5 \pm 6.3 \mathrm{~mm} \mathrm{Hg}\end{array}$ & $\begin{array}{r}20.9 \pm 4.2 \\
30.8 \dagger \pm 5.1 \\
26.3 \pm 4.1 \\
9.9 \dagger \pm 2.5\end{array}$ & $\begin{array}{l}1.2 \pm 0.3 \\
0.9 \pm 0.2 \\
0.9 \pm 0.3 \\
1.6 \pm 0.8\end{array}$ & $\begin{array}{l}3.4 \pm 0.5 \\
2.4 \dagger \pm 0.3 \\
2.5 \pm 0.3 \\
5.6 \dagger \pm 1.3\end{array}$ \\
\hline \multicolumn{4}{|l|}{ Forelimb experiments } \\
\hline $\begin{array}{l}\text { Control } \\
\text { BP }+26.2 \pm 6.2 \mathrm{~mm} \mathrm{Hg} \\
\text { Control } \\
\text { BP }-54.3 \pm 9.7 \mathrm{~mm} \mathrm{Hg}\end{array}$ & $\begin{array}{l}4.7 \pm 0.6 \\
8.6 \dagger \pm 2.0 \\
7.3 \pm 2.3 \\
4.0 \dagger \pm 1.3\end{array}$ & $\begin{array}{l}14.0 \pm 2.1 \\
11.3 \pm 2.9 \\
10.6 \pm 2.1 \\
16.2 \dagger \pm 4.6\end{array}$ & $\begin{array}{l}13.2 \pm 2.7 \\
10.7 \pm 3.1 \\
12.9 \pm 3.6 \\
12.7 \pm 4.8\end{array}$ \\
\hline Hindlimbs without ligation & $\begin{array}{l}\text { Venous } \\
\text { outflow }\end{array}$ & TR & \\
\hline $\begin{array}{l}\text { Control } \\
\text { BP }+30 \pm 13.0 \mathrm{~mm} \mathrm{Hg} \\
\text { Control } \\
\mathrm{BP}-49 \pm 11.0 \mathrm{~mm} \mathrm{Hg}\end{array}$ & $\begin{array}{l}16.9 \pm 2.4 \\
30.7 \dagger \pm 1.0 \\
30.7 \pm 3.2 \\
14.9 \dagger \pm 0.9\end{array}$ & $\begin{array}{l}6.1 \pm 0.6 \\
5.0 \dagger \pm 0.3 \\
5.1 \pm 0.4 \\
7.4 \dagger \pm 1.1\end{array}$ & \\
\hline
\end{tabular}

* $B P=$ blood pressure $; T R=$ total $\operatorname{limb}$ vascular resistance.

t Significant change from control values $(\mathrm{p}<0.05)$ by paired $t$ test. 
decreased from 41 to $33 \mathrm{ml}$ per minute when femoral arterial flow was shunted through the rotameter as retrograde flow. In all 7 retrograde experiments simultaneously measured retrograde flow and venous outflow averaged $86.5 \pm 16.4 \mathrm{ml}$ and $26.9 \pm 3.2 \mathrm{ml}$, respectively. Local arterial pressure distal to the femoral arterial obstruction fell to low levels (average $8 \mathrm{~mm} \mathrm{Hg}$ ) during retrograde flow measurements.

Changes in retrograde blood flow reflected changes in systemic arterial pressure during exercise or intra-aortic infusions of bradykinin or norepinephrine; changes in collateral resistance (systemic minus local arterial pressure divided by retrograde flow) were absent or negligible. Venous outflow increased during exercise or intraaortic infusion of bradykinin and decreased during intra-aortic infusion of norepinephrine; venous outflow changes were usually opposite in direction to retrograde flow changes.

Oxygen content of femoral arterial blood below the obstruction. The oxygen content of blood from the artery distal to the obstruction was compared to the oxygen content of simultaneously drawn common carotid arterial blood in 11 acutely and 21 chronically ligated dogs. Average oxygen content of blood from the femoral artery below the ligation was $17.6 \pm 0.8 \mathrm{ml}$ per $100 \mathrm{ml}$ of blood in the acute experiments, the same as the average oxygen content $(17.6 \pm 0.7 \mathrm{ml}$ per $100 \mathrm{ml})$ of carotid arterial blood $(\mathrm{p}>0.5)$. In the chronically ligated dogs, average oxygen content of blood from the femoral artery below the obstruction and of carotid arterial blood was also the same (both $17.4 \pm 0.9 \mathrm{ml}$ per $100 \mathrm{ml}$ of blood, $\mathrm{p}>0.5$ ).

Oxygen content of collateral venous blood. The oxygen content of collateral venous blood was compared to the oxygen content of blood simultaneously collected from the femoral vein of the opposite limb. In the acutely ligated dogs, collateral venous blood oxygen content averaged $6.5 \pm 0.9$ compared to $10.8 \pm 0.8 \mathrm{ml}$ per $100 \mathrm{ml}$ for femoral venous blood from the opposite limb $(\mathrm{p}<0.001)$. In the chronically ligated dogs, collateral venous blood oxygen content averaged $10.7 \pm 1.2$ compared to $12.6 \pm 1.4 \mathrm{ml}$ per $100 \mathrm{ml}$ for femoral venous blood from the contralateral $\operatorname{limb}(\mathrm{p}<$ $0.01)$. In the forelimb experiments, collateral venous blood oxygen content was $11.0 \pm 0.8 \mathrm{com}$ pared to $13.1 \pm 1.2 \mathrm{ml}$ per $100 \mathrm{ml}$ for brachial venous blood from the opposite limb $(p<0.05)$.

\section{Discussion}

In this study of collateral blood flow and vascular resistance, two assumptions were made. First, the venous outflow of the limb was assumed to be an adequate reflection of its arterial inflow. In the experiments in which arterial inflow and venous outflow of limbs with unobstructed main arteries were measured simultaneously, venous outflow was found to represent a large percentage of the arterial inflow. No significant changes in the ratio of venous outflow to arterial inflow were found during three grades of exercise. Therefore, venous outflow measurements apparently provide a good indication of arterial inflow to the limb under these circumstances. Green, Cosby, and Radzow (13) have shown that venous outflow may not parallel arterial inflow when there are large alterations in systemic arterial pressure. Our experiments in which large systemic arterial pressure changes were produced may therefore contain inaccurate data, although the directional changes should be correct.

The second assumption was that the collateral arteries empty into the femoral artery below the obstruction and do not feed a separate capillary bed that empties directly into the femoral venous system. If a second collateral system existed that emptied directly into the femoral vein, venous outflow from the limb would include the blood flow through the two collateral systems. Although the pressure difference can be measured for each system, the inability to measure flow separately through each collateral system would not allow resistance calculations to be made. Only circumstantial evidence can be offered for the assumption that all the collateral vessels empty into the femoral artery below the obstruction. The retrograde flow experiments demonstrated a very large retrograde flow from the femoral artery below the site of ligation; this retrograde flow averaged more than three times the simultaneously measured venous outflow from the limb. These data would indicate that if any collateral vessels do empty into the femoral venous system, the amount of blood they carry is small in comparison with the collateral blood flow emptying into the femoral artery below the obstruction site.

The first question asked in this study concerns what procedures increase or decrease collateral blood flow. Exercise, intra-aortic and intra-arte- 
rial bradykinin, intravenous catecholamines, elevation of systemic arterial pressure, and an ischemic stimulus (aortic occlusion) produced large increases in collateral blood flow. Intravenously administered norepinephrine caused vasodilatation, presumably as a reflex sympathetic response to the rise in systemic arterial pressure. Epinephrine often caused systemic arterial pressure elevations, but it is also known to have a direct vasodilating effect on skeletal muscle blood vessels in physiological concentrations. Isoproterenol intravenously produced small but sometimes significant increases in collateral flow. Thulesius (5) found that intravenous vasodilator drugs that lower systemic arterial pressure usually lead to a decrease in blood flow in a limb with an obstructed main artery. Our results indicate the possible usefulness of systemically administered vasopressor drugs for increasing collateral blood flow.

A decrease in collateral blood flow was produced by intra-arterial (below the obstruction) epinephrine and norepinephrine and also by depression of systemic arterial pressure. Intraaortic norepinephrine and epinephrine did not decrease collateral blood flow, since the agent reached the entire lower half of the body and usually raised systemic arterial pressure.

The second question asked in this study was whether collateral vessels dilate and constrict. Changes in collateral vascular resistance were used to reflect dilatation or constriction of the collateral vessels. Intra-aortic infusions of bradykinin, exercise, systemic arterial pressure elevation, and intravenously administered norepinephrine decreased collateral resistance in the hindlimb experiments. Direct action on the collateral vessels was suggested by the difference between the effects of intra-aortic (above the obstruction) and intra-arterial (below the obstruction) bradykinin infusions. The same concentration of the drug was administered by each route ensuring that a larger amount would reach the local hindlimb peripheral vessels by the intra-arterial route. However, the intra-aortic injections, which would reach the collateral arteries, produced much greater increases in blood flow. For instance, in the hindlimb experiments with acute ligation of the femoral artery, bradykinin infused below the ligation increased blood flow by only 6.6 (from 31.3 to 37.9) $\mathrm{ml}$ per minute, whereas infusion into the aorta increased blood flow by 32.9 (from 31.2 to
64.1) $\mathrm{ml}$ per minute. If a collateral arterial bed that empties separately into the femoral vein instead of into the femoral artery were to be invoked to explain this difference, such a bed would have to be much larger than the vascular bed fed by the femoral artery (this assumes that the bradykinin infusion intra-aortically would reach both collateral vascular beds, whereas the intra-arterial infusion would reach the femoral arterial bed only). As mentioned previously, the retrograde flow studies do not support the existence of a collateral vascular bed of this size emptying separately into the femoral venous system.

The mechanism of the vasodilatation of the collateral vessels during muscular exercise is not explained by these experiments. Arterial dilatation above the area of exercising muscle has been attributed to a wave of relaxation traveling centrally along the smooth muscle fibers of the vessel wall, the impulse carried by the muscle fibers themselves (14).

A significant increase in collateral resistance in the hindlimbs of acutely ligated dogs occurred during systemic arterial pressure depression. Three of the 5 chronically ligated dogs also showed an increase in collateral resistance during systemic arterial pressure depression, but this was not statistically significant.

Lambert $(6,7)$ performed acute studies on the dog's hindlimb but concluded that the collateral vasculature was not reactive. The administration of vasodilator drugs into the iliac artery instead of the aorta may have prevented the collateral vessels in his experiments from being affected; also his operative procedure may have compromised the collateral circulation. Thulesius (5) studied the collateral circulation by measuring the collateral and peripheral resistance in the cat hindlimb. He found that acute femoral arterial occlusions resulted in a peripheral vascular bed that was nonreactive to the vasodilator effects of intraarterial acetylcholine or exercise, but that the collateral vessels could be dilated by intra-aortic acetylcholine. In his chronic experiments, the collateral circulation reacted as it did in the present study. The lack of reactivity in his acute experiments was attributed by him to a fully dilated peripheral vascular bed secondary to an assumed ischemia.

In the present experiments, after arterial occlusion, blood flow and arterial pressure below the 
obstruction fell. Immediately after this initial drop, a simultaneous rise in blood flow and pressure occurred, indicating either dilatation of the existing collateral vessels or opening of new channels. Although blood flow and arterial pressure below the obstruction became stable within a few minutes, other investigators $(3,15)$ have reported that collateral blood flow and pressure distal to the obstruction continue to increase for weeks. The larger blood flow and lower collateral resistance found in our chronically ligated dogs as compared to our acute experiments agree with these reports. Increases in blood flow during exercise occurred in both acutely and chronically ligated dogs, but the larger blood flows attained during exercise in the chronically ligated dogs also indicate that a greater capacity for collateral blood flow had developed.

The demonstration of the reactive hyperemia phenomenon indicates that the limb with an obstructed main artery can increase its blood flow after an ischemic procedure. Flow debt repayments were of the same order of magnitude but with a lower peak flow and a longer duration of debt repayment than in limbs with unobstructed arteries. The latter data indicate that despite a reduced capacity for blood flow in these limbs, ischemic debts can be repaid; however, a longer period of time is required.

The forelimb experiments represent an attempt to limit severely the amount of collateral blood flow in a limb. Collateral blood flow and blood pressure distal to the combined subclavian and axillary arterial obstructions were lower than in the hindlimb studies; after exercise, the lowered blood pressure distal to the obstruction returned to previous levels slowly as compared with the hindlimb experiments. This may represent a continued dilatation of the peripheral vasculature under the stimulus of the metabolic debt developed during exercise. Local forelimb vascular resistance could be raised or lowered significantly by the procedures used, but the associated changes in blood flow were small in quantity. A significant increase in collateral resistance occurred during systemic arterial pressure depression as in the hindlimb experiments. The increase in collateral resistance during muscle contractions could be explained by a mechanical limitation of blood flow. Collateral resistance in the forelimb was not sig- nificantly changed by procedures that did produce decreases in the hindlimb experiments, indicating presumable full dilatation of forelimb collateral vessels. Since local vascular resistance could be decreased, the limited collateral vasculature is evidently the major factor limiting blood flow to the limb in these experiments.

Retrograde blood flow experiments were performed to evaluate the method for studying collateral blood flow and vascular reactivity (15). The fact that the oxygen content of retrograde blood is the same as that of systemic arterial blood demonstrates that this blood comes directly from the collateral arterial vessels and has not passed through a capillary bed. Retrograde blood flow was not considered to be an adequate indication of collateral flow for two reasons. First, an inverse relationship between retrograde blood flow and venous outflow was found with the procedures tested. It was assumed that decreases in venous outflow occurred during measurement of retrograde flow because blood was deflected from the vascular bed below the obstruction by opening the femoral artery to the lower resistance of the rotameter circuit. On the other hand, a decrease in local limb resistance would probably cause part of the retrograde blood flow to proceed onward to supply the hindlimb. Second, the technique necessary for the measurement of retrograde flow creates an abnormal situation. Opening of the rotameter circuit not only produces a large pressure difference across the collateral vessels but also probably induces an almost complete vasodilatation, since no further decrease in collateral resistance could be found with any of the procedures used. Retrograde blood flow measurements were consistently much larger than those obtained when only venous outflow was measured, lending support to this conclusion.

The results of various studies $(5,13,16)$, including the present one, indicate that collateral vessels react as other limb vessels do to procedures that cause vasodilatation and vasoconstriction. The differences in collateral vascular reactivity reported are evidently due to variations in the experimental preparations used in the different studies. The dog hindlimb in the present experiments presumably contained both collateral vessels and local vascular beds capable of further vasodilatation. The forelimb preparation evidently con- 
tained a limited, dilated collateral vasculature capable of very little, if any, further vasodilatation, but its local vascular bed had significant capacity for further vasodilatation. Thulesius' (5) acute cat hindlimb preparation, on the other hand, may have contained a fully dilated local vasculature with collateral arterial vessels capable of further vasodilatation. These three different experimental situations may each have a clinical counterpart in human arterial obstructive disease of various grades of severity; this possibility bears investigation.

\section{Summary}

The effects of several different procedures on collateral blood flow and vascular resistance were investigated in the dog hindlimb and forelimb. In the hindlimbs with acutely or chronically ligated main arteries, collateral flow could be increased and vascular resistance decreased by vasodilator procedures in a manner qualitatively similar to findings in the vasculature of limbs with unobstructed arterial inflow. Vasoconstrictor procedures decreased collateral blood flow, but significant increases in collateral vascular resistance occurred only during systemic arterial pressure depression in the acutely ligated dogs. An interesting finding was the increase in collateral flow and the decrease in collateral resistance with intravenous norepinephrine. A limited but fully dilated collateral vasculature was evidently present in the forelimb preparation, since vasodilator stimuli lowered local vascular resistance without decreasing collateral resistance.

Retrograde blood flow was also evaluated by measuring the blood flow from the femoral artery below its ligation site; oxygen studies showed the blood from arteries below an obstruction had not passed through a capillary bed. Measurement of retrograde blood flow by this method was not considered to be reliable for the study of collateral vessel reactivity.

It is concluded that collateral vessels react to various vasoactive procedures in a manner similar to other blood vessels in the limbs. Differences in the reactions of the collateral vasculature reported in this and other studies may be explained by variations in the amount and vasomotor state of the collateral vasculature resulting from the different experimental preparations used.

\section{References}

1. Shepherd, J. T. The effect of acute occlusion of the femoral artery on the blood supply to the calf of the leg before and after release of sympathetic vasomotor tone. Clin. Sci. 1950, 9, 355.

2. Winsor, T., J. H. Payne, N. Rudy, and J. O. Beatty. Collateral circulation in health and disease. Arch. Surg. 1957, 74, 20.

3. John, H. T., and R. Warren. The stimulus to collateral circulation. Surgery 1961, 49, 14.

4. Goetz, R. H. On the measurement of the collateral circulation, with special reference to the indications for sympathectomy. Angiology 1950, 1, 201.

5. Thulesius, O. Hemodynamic studies on experimental obstruction of the femoral artery in the cat. Acta physiol. scand. 1962, 57 (suppl. 199), 1.

6. Lambert, J. Effets différents de l'injection intraartérielle de substances vasodilatatrices sur la circulation dans le muscle strié irrigué par voie normale ou par voie collatérale. Arch. int. physiol. 1961, 69, 401.

7. Lambert, J. Modifications hémodynamiques dans le muscle strié irrigué par voie collatérale, aprés injections intra-artérielles de substances vasodilatatrices. Arch. int. physiol. 1961, 69, 404.

8. Miller, M. E., G. C. Christensen, and H. E. Evans. Anatomy of the Dog. Philadelphia, W. B. Saunders, 1964.

9. Coffman, J. D., and D. E. Gregg. Reactive hyperemia characteristics of the myocardium. Amer. J. Physiol. 1960, 199, 1143.

10. Van Slyke, D. D., and J. M. Neill. The determination of gases in blood and other solutions by vacuum extraction and manometric measurement. $\mathrm{J}$. biol. Chem. 1924, 61, 523.

11. Green, H. D., R. N. Lewis, N. D. Nickerson, and A. L. Heller. Blood flow, peripheral resistance and vascular tonus, with observations on the relationship between blood flow and cutaneous temperature. Amer. J. Physiol. 1944, 141, 518.

12. Snedecor, G. W. Statistical Methods, 5th ed. Ames, Iowa State College Press, 1956.

13. Green, H. D., R. S. Cosby, and K. H. Radzow. Dynamics of collateral circulations. Amer. J. Physiol. 1944, 140, 726.

14. Hilton, S. M. A peripheral arterial conducting mechanism underlying dilatation of the femoral artery and concerned in functional vasodilatation in skeletal muscle. J. Physiol. (Lond.) 1959, 149, 93.

15. Eckstein, R. W., D. E. Gregg, and W. H. Pritchard. The magnitude and time of development of the collateral circulation in occluded femoral, carotid and coronary arteries. Amer. J. Physiol. 1941, 132, 351.

16. Dornhorst, A. C., and E. P. Sharpey-Schafer. Collateral resistance in limbs with arterial obstruction: spontaneous changes and effects of sympathectomy. Clin. Sci. 1951, 10, 371. 